\title{
Optimized Batrachochytrium dendrobatidis DNA extraction of swab samples results in imperfect detection, particularly when infection intensities are low
}

\author{
Laura A. Brannelly ${ }^{1, *}$, Daniel P. Wetzel ${ }^{2}$, Matt West ${ }^{3,4}$, Corinne L. Richards-Zawacki ${ }^{2}$ \\ ${ }^{1}$ One Health Research Group, Faculty of Veterinary and Agricultural Sciences, \\ University of Melbourne, Werribee, Victoria 3030, Australia \\ ${ }^{2}$ Department of Biological Sciences, University of Pittsburgh, Pittsburgh, Pennsylvania \\ 15260, USA \\ ${ }^{3}$ Department of Biological Sciences, University of Melbourne, Melbourne, Victoria 3010, \\ Australia \\ ${ }^{4}$ NESP Threatened Species Recovery Hub, University of Melbourne, Melbourne, Victoria \\ 3010, Australia \\ *Corresponding author: laura.brannelly@unimelb.edu.au
}

Running Page Head: Brannelly et al.: Optimized $B d$ DNA extraction method

ABSTRACT: Accurate detection of the amphibian fungal pathogen Batrachochytrium dendrobatidis $(B d)$ is critical for wildlife disease research; however, false negatives in detection do occur. Here we compared different DNA extraction methods to determine the threshold for $B d$ detection and identify an optimal extraction method to improve detection and quantification of the pathogen. We extracted both lab-created cell suspension standards using PrepMan Ultra, Chelex resin, and 3 spin column DNA extraction kits (Qiagen DNeasy Blood and Tissue, Zymo Quick DNA miniprep, and IBI gMAX mini kit), and further compared extraction methods using field-collected samples. We found that when extracting $B d$ DNA from cells in lab-created culture, the spin column extraction methods and PrepMan Ultra were equivalent, while the resin method detected higher $B d$ DNA quantities, especially at higher loads. However, when swabs from live animals were analyzed, low $B d$ quantities were more than twice as likely to be detected using a spin column extraction than with the PrepMan Ultra extraction method. All tested spin column extraction methods performed similarly across both field and lab samples. Samples containing low $B d$ quantities yielded inconsistent detection and quantification of $B d$ DNA copies regardless of extraction method. To manage imperfect detection of $B d$, we suggest that presence/absence analyses are more informative than attempting to quantify $B d$ DNA when quantities are low. Overall, we recommend that a cost-benefit analysis of target species susceptibility and epidemiology be taken into 
consideration when designing an experiment to determine the most appropriate DNA extraction method to be used, because sometimes detecting low $B d$ quantities is imperative to the study, whereas in other situations, detecting low DNA quantities is less important.

KEY WORDS: Chytridiomycosis $\cdot$ Amphibian disease $\cdot$ Chelex resin $\cdot$ Detection threshold · DNA extraction · False negative · Qiagen DNeasy Blood and Tissue · Pathogen detection · PrepMan Ultra

\section{INTRODUCTION}

The use of DNA extraction and polymerase chain reaction (PCR) is an important diagnostic tool for detecting pathogens in both human and wildlife health. One disease of aquatic organisms for which pathogen DNA detection is particularly important is amphibian chytridiomycosis, caused by 2 fungal species, Batrachochytrium dendrobatidis $(B d)$ and B. salamandrivorans (Bsal) (Longcore et al. 1999, Martel et al. 2013). To detect these cutaneous pathogens, researchers typically collect a skin swab from potentially infected animals, then extract DNA contained on the swab, and use quantitative PCR (qPCR) to detect the presence and quantity of pathogen DNA (Boyle et al. 2004, Hyatt et al. 2007). qPCR is a more sensitive method for detecting small quantities of DNA within a sample compared to traditional PCR and gel visualization (Garland et al. 2011), or visualizing infection using histology (Hyatt et al. 2007). Using lab-created, serially diluted standards of $B d$ DNA, qPCR techniques are capable of detecting quantities of as low as $0.1 B d$ cell per reaction well (Boyle et al. 2004). However, in live $B d$-infected animals with low infection intensity, pathogen detection via qPCR frequently yields inconsistent and false negative results (Bletz et al. 2015, SabinoPinto et al. 2019). The ability to detect low-level fungal infections can be important for wildlife health assessment, as well as for accurately assessing clinical laboratory infection experiments (Byrne et al. 2018). Therefore, understanding the limitations of different extraction methods is of considerable importance to the outcome of wildlife disease research.

Recent studies indicate that disease research typically has a high degree of imperfect sampling in field-based surveys. Two common sources of imperfect disease sampling are sampling bias (when animals of different disease states are captured at different rates, a concern that affects most field studies) and imperfect disease detection in sampled individuals (false negatives; Nusser et al. 2008, Miller et al. 2012, DiRenzo et al. 2018). Several methods have been proposed to address the problem of false negatives in wildlife disease detection: (1) the use of analytical methods (such as Bayesian modeling for occupancy estimation) to account for imperfect disease detection (Miller et al. 2012), (2) increasing the number of sample replicates collected per individual (DiRenzo et al. 2018), and (3) increasing pathogen detection efficiency through improvement of the DNA detection methodology.

There are 2 commonly used methods for extracting $B d$ DNA from skin swabs for $B d$ detection: spin column extraction kits and non-spin column methods. Spin column kits wash the DNA prior to elution and yield a purified DNA product with presumably fewer PCR inhibitors. Non-spin column extraction methods are often less expensive, less time intensive, and do not involve DNA wash steps. Non-spin column methods typically 
involve steps to lyse the cells and inactivate inhibitors, then DNA dissolved in the lysate is used as the template for PCR. Currently, the extraction method identified as 'best' for detecting low $B d$ infection quantity is the Qiagen DNeasy Blood and Tissue spin column extraction kit (Qiagen no. 69504; Bletz et al. 2015, Sabino-Pinto et al. 2019). This spin column method produces purified DNA but is relatively expensive and time intensive (several hours per extraction, although depending on format purchased, up to 96 samples can be extracted simultaneously). Another extraction method that is frequently used for $B d$ DNA detection due to its low cost and quick extraction time is the PrepMan Ultra extraction reagent method. The PrepMan Ultra does not include a spin column or wash steps and produces DNA that is relatively impure (has a high potential for PCR inhibition). This method is relatively inexpensive and can be faster $(<20 \mathrm{~min}$ to extract 1 sample) in comparison to spin column kits, but previous studies have found the method to be less consistent than spin column extractions, particularly at low $B d$ quantities (specifically compared to the Qiagen DNeasy Blood and Tissue kit) (Bletz et al. 2015, Sabino-Pinto et al. 2019).

While the Qiagen DNeasy Blood and Tissue kit is the current standard for $B d$ extraction (based on previous comparative studies; i.e. Bletz et al. 2015, Sabino-Pinto et al. 2019), to our knowledge there has been no standardized comparison of this method with less expensive and less time-intensive spin column extraction methods, nor have these methods been compared using samples from live animals. Crucially, skin swab samples contain additional organic compounds compared to samples produced from pure $B d$ cultures, which might lead to differences between lab-produced pure $B d$ samples and field-collected samples from live animals. It is possible that these organic compounds could influence detection and quantification of $B d$ DNA, even if it does not directly result in observable PCR inhibition. To date, we have little understanding as to how extraction methods can affect $B d$ detection in live animal samples with all else being equal (i.e. controlled sample collection methods and qPCR protocol), and therefore it is paramount to compare extraction methods using field samples. This issue might be particularly important for samples that contain low concentrations of $B d$, which is where extraction methods are known to vary in efficiency.

In this study, we compared 5 different DNA extraction methods to determine which was the most efficient method for detecting and quantifying $B d$ DNA on amphibians. Our comparison of extraction methods had 3 aims. First, we sought to quantify the threshold of detection using the previously determined most efficient extraction kit, Qiagen DNeasy Blood and Tissue (Bletz et al. 2015, Sabino-Pinto et al. 2019), by extracting lab-created $B d$ standards of known quantity (using a serially diluted $B d$ zoospore suspension). Next, we compared the detection of $B d$ DNA in lab-created $B d$ standards among different extraction methods. We compared 3 commonly used spin column extraction methods (Qiagen DNeasy Blood and Tissue, Zymo Quick DNA miniprep, and IBI gMAX mini kit), and also compared 2 commonly used non-spin column methods (PrepMan Ultra and Chelex resin) with a spin column extraction method (Qiagen DNeasy Blood and Tissue). Finally, we used live-animal field-collected $B d$ swabs to test for differences in the quantity of $B d$ detected across extraction methods. Despite the fact that the majority of $B d$ studies using qPCR for disease detection have investigated live animals (field or lab-based), controlled comparisons of DNA extraction methods have been limited to lab-created $B d$ cultures. Ultimately, our aim is to determine 
the threshold of $B d$ detection for each of these methods so that we can better understand the detection limits and likelihood of false negative results in $B d$ infection studies. This also has implications for researchers deciding which extraction method to use for a given research project by revealing the scenarios under which more efficient (and more expensive) extraction kits are recommended, versus situations where or less expensive and less efficient $B d$-detection might be sufficient.

\section{MATERIALS AND METHODS}

\subsection{Threshold of $B d$}

We used a stock $B d$ culture maintained in TGHL broth (16 g Tryptone, 2 g gelatin hydrolysate, $4 \mathrm{~g}$ lactose, $1000 \mathrm{ml}$ water) in a $50 \mathrm{ml}$ cell-culture flask at $4^{\circ} \mathrm{C}$ to generate a serial dilution set of $B d$ standards. The $B d$ culture originated from the Sierra Nevada Mountains, USA (MYLF_16343, Milestone Basin, Sequoia and King's Canyon National Park, CA, USA from Rana muscosa, 2016, collected by J. Voyles and M. Toothman). Two $1 \mathrm{ml}$ samples were removed from the culture flask and filtered through an autoclaved coffee filter (Harris coffee filter papers, approx. $20 \mathrm{~nm}$ ) to remove zoosporangia while zoospores passed through. From each filtered sample, we took 4 aliquots of $10 \mu$ to estimate zoospore concentration using a hemocytometer. We averaged these zoospore counts, then used a serial dilution of each $1 \mathrm{ml}$ sample to create 2 sets of $6 B d$ standards, and pipetted the standard suspension (3-7 $\mu$, depending on concentration) onto a rayon-tipped swab (M113, Medical and Wire). For each of the 2 sets of standards, 3 replicate swabs were inoculated with the $B d$ standard suspension to yield samples containing $0.1,1,10,100,1000$, and 10000 zoospore equivalents (ZEs) per swab (a total of 36 samples). The samples were stored frozen $\left(-20^{\circ} \mathrm{C}\right)$ in individual 1.5 $\mathrm{ml}$ microcentrifuge tubes until they were extracted.

Samples were extracted using the Qiagen DNeasy Blood and Tissue extraction kit (Qiagen no. 69504) using individual extraction columns. We followed instructions for animal tissue extraction with the following minor modifications. First, we incubated the samples for $1 \mathrm{~h}$ at $56^{\circ} \mathrm{C}$ with intermittent vortexing to lyse the cells. Second, during the elution step, we let the filters incubate for $5 \mathrm{~min}$ and then eluted the extraction twice with $100 \mu \mathrm{l}$ of elution buffer, for a total elution volume of $200 \mu$ l. Eluted DNA was stored frozen at $-20^{\circ} \mathrm{C}$. During each round of extractions (consisting of 23 samples), we extracted a blank sample (no $B d$ on a clean swab) as a negative control. Eluted DNA was not diluted prior to qPCR.

We used qPCR (Quantstudio 3 System, Applied Biosystems) to amplify and quantify the $B d$ DNA in each sample. We followed a modified protocol for qPCR cycling and used primers developed for detecting $B d$ (Boyle et al. 2004, Hyatt et al. 2007). We used a $25 \mu \mathrm{l}$ reaction volume, with $5 \mu$ l of template DNA, $12.5 \mu$ l of lo-ROX $2 \times$ master mix (SensiFast, Bioline), and a final reaction concentration of $900 \mathrm{nM}$ ITS1-3, $900 \mathrm{nM}$ 5.8S Chytr, $240 \mathrm{nM}$ Chytr MGB2 FAM-labeled probe, $400 \mathrm{ng} \mu \mathrm{l}^{-1} \mathrm{BSA}$, and 1/3× internal positive control probe (IPC) (Applied Biosystems TaqMan exogenous IPC). Each qPCR reaction plate included a series of 7 plasmid-based $B d$ standards (purchased from Pisces Molecular, ITS copies containing 4.2, 42, 420, 4200, 42000,420000 , and 4200000 DNA copies per reaction). Zoospore quantity added refers to the number of known 
zoospores added to the samples prior to extraction, and DNA copies refers to the number of $B d$ DNA copies present as determined by qPCR and extrapolated, taking elution volume and dilution of template DNA in qPCR into account, to estimate the number of $B d$ DNA copies extracted from the whole swab/sample (i.e. we multiplied the DNA copies detected by qPCR in a $5 \mu$ of template extracted DNA by 40 , as only $1 / 40$ of the total $200 \mu \mathrm{l}$ extraction volume was quantified). We used a liberal definition of what we considered a positive sample for this study: a qPCR reaction well was considered positive for $B d$ if at least $2 B d$ ITS copies were detected within the sample, and a sample was considered positive if at least 1 of the 3 replicate qPCR wells was positive. If any sample replicate was determined to be $B d$ positive, the triplicate reactions were averaged (including those where no $B d$ was detected, representing 0 DNA copies). If the sample was considered negative for $B d$, the $B d$ DNA copies was coded as 0 for that sample. We chose this liberal definition of positive samples (Brannelly et al. 2012b, Chatfield et al. 2013) to demonstrate the limits on detecting low $B d$ loads, which is of particular interest in this study, because it is at these low 'infection' loads of detection that the extraction kits are known to differ. Low loads are of particular interest in pathogen detection studies.

\subsection{Extraction method comparison}

\subsubsection{Comparison of spin column and non-spin column extraction methods}

We compared the efficiency of the Qiagen DNeasy Blood and Tissue extraction kit, the Prepman Ultra DNA extraction, and Chelex resin extraction. The PrepMan Ultra (PrepMan, Applied Biosystems no. 4318930, per sample) extraction method is the most commonly used non-spin column DNA extraction method for detecting $B d$ DNA on swabs. Another non-spin column extraction method commonly used in commercial labs is a Chelex resin-based extraction (Chelex 100 resin, Bio-Rad no. 1422822; Walsh et al. 1991), which is also relatively inexpensive. For additional PrepMan Ultra and Chelex resin extraction trials where we tested the effects of using beads in the PrepMan Ultra extraction, and the effect of using Proteinase $\mathrm{K}$ in the Chelex resin extraction, see Text $\mathbb{S} 1$ in the Supplement at www.int-res.com/articles/suppl/d000p000_supp.polf.

For the PrepMan Ultra, Chelex resin, and Qiagen DNeasy Blood and Tissue extraction method comparison, we first made a new set of $6 B d$ dilution standards (as described above; $0.1,1,10,100,1000$, and $10000 B d$ ZEs added to each swab in triplicate, a total of 18 samples per extraction method) from a $B d$ strain collected in Australia (MittaMitta-Lspenceri-2018-LB Northeast Victoria, from Litoria spenceri, 2016, collected by M. West and L. Berger).

We followed the Qiagen DNeasy Blood and Tissue extraction method as described above. The PrepMan Ultra extraction method followed the manufacturer's directions, which included: adding $50 \mu \mathrm{l}$ of PrepMan Ultra and 30-40 mg of $0.5 \mathrm{~mm}$ silica beads to each sample (although the bead beating step might not be necessary; see Text S1), homogenizing samples (using a cell homogenizer) for $2 \mathrm{~min}$ at 1400 oscillations s${ }^{-1}$, incubating samples at $95^{\circ} \mathrm{C}$ to lyse the cells for $10 \mathrm{~min}$, and collecting and storing the supernatant at $-20^{\circ} \mathrm{C}$. For the Chelex resin extraction method, we added $197 \mu \mathrm{l}$ of $5 \%$ Chelex resin slurry and $3 \mu \mathrm{l}$ of Proteinase K (Qiagen no. 19131) to each sample (although the Proteinase K addition might not be a necessary step; see Text S1). 
Samples were incubated at $56^{\circ} \mathrm{C}$ to for $60 \mathrm{~min}$ with intermittent vortexing, then incubated at $95^{\circ} \mathrm{C}$ for $15 \mathrm{~min}$. The supernatant was then collected and stored at $-20^{\circ} \mathrm{C}$.

DNA extract from the PrepMan Ultra and Chelex resin extraction methods was diluted 6:100 in molecular grade water (due to the possibility of inhibitors in the sample; Garland et al. 2011; see Text S1), and the diluted DNA was used as a template in qPCR reactions, as described above, in triplicate, and DNA copies are presented as whole swab estimates (multiplied by 40 for Qiagen DNeasy Blood and Tissue Kit, 166.66 for PrepMan Ultra, and 666.66 for Chelex resin). For each extraction method, 3 negative controls (clean swabs with no $B d$ ) were extracted alongside the $B d$-containing samples. The qPCR protocol was the same as listed above for these samples, but the qPCR was performed on a Rotorgene Q (Qiagen) (see Text S1 for additional information on nonspin column trials).

\subsubsection{Comparison of spin column extraction methods}

We compared 3 spin column extraction methods (Qiagen DNeasy Blood and Tissue; as above), IBI gMAX mini genomic DNA kit (IBI Scientific no. IB47281), and Zymo Quick DNA miniprep extraction kit (Zymo Research no. D3024) using samples of known $B d$ quantity (lab-created $B d$ standards). We made 6 new $B d$ zoospore standards (as described above; $0.1,1,10,100,1000$, and $10000 B d$ ZEs added to each swab in triplicate, a total of 18 samples per extraction method; MYLF_43 $B d$ strain as above). We included $3 B d$ negative samples (clean swabs) for each extraction method.

The IBI gMAX mini extraction kit is similar to the Qiagen DNeasy Blood and Tissue kit protocol. We extracted samples following the manufacturer's protocol for tissue, except that incubation time for cell lysis with Proteinase K was $1 \mathrm{~h}$, and at the DNA elution step we let the filters incubate for $5 \mathrm{~min}$ before we eluted the extraction twice with $100 \mu \mathrm{l}$ of elution buffer, for a total elution volume of $200 \mu \mathrm{l}$.

The Zymo Quick DNA miniprep kit is also a spin column extraction kit but has fewer steps and reagents than the Qiagen DNeasy Blood and Tissue kit and IBI gMAX mini extraction kit. We followed the manufacturer's extraction protocol for buccal swab extractions, which differed from the previous methods, as there was no Proteinase K digestion step and cell lysis incubation was for $10 \mathrm{~min}$ at room temperature. We modified the DNA elution step as above, where we let the filters incubate for $5 \mathrm{~min}$ and then eluted the extraction twice with $100 \mu \mathrm{l}$ of elution buffer, for a total elution volume of $200 \mu 1$.

Eluted DNA from spin-column extractions was not diluted prior to qPCR, and DNA copies are presented as whole swab estimates (i.e. multiplied by 40, as described above, for all spin-column methods); all qPCR reactions for spin column extraction samples were run in triplicate. While we used 2 different strains for the comparison of the spin column extraction methods and the non-spin column extraction methods, we extracted both standards using the Qiagen DNeasy Blood and Tissue kit protocol, which standardizes the 2 extraction trials and allows comparison between them.

\subsection{Comparison of extraction method using field-collected samples}

PrepMan Ultra and Qiagen DNeasy extraction methods are the most common extraction methods and have been compared previously under laboratory settings. Here we compared them using live animal skin swabs to ensure that differences observed in 
the lab translated into the field. Wild frogs (Rana catesbeiana and $R$. clamitans) were caught as available near Linesville, Pennsylvania (USA), in July 2017 with a clean nitrile gloved hand. Animals $(\mathrm{n}=39)$ were simultaneously swabbed with 2 swabs 45 times each ( 5 strokes on each the dorsum, venter, sides, thighs, hands, and feet), and swabs were rotated over the frog skin surface during sample collection. Swabs were then stored in sealed $1.5 \mathrm{ml}$ microcentrifuge tubes at $-20^{\circ} \mathrm{C}$ until DNA extraction, where $1 \mathrm{swab}$ from each animal was haphazardly assigned to either the PrepMan Ultra or the Qiagen DNeasy Blood and Tissue DNA extraction method.

To compare spin column extraction kits using live animal swabs we chose to compare the Qiagen DNeasy extraction method with the Zymo Quick DNA miniprep kit. The Qiagen DNeasy kit is the most commonly used of the spin column methods. We chose to compare it with the Zymo kit because the Zymo kit is cheaper, quicker, and has fewer wash steps, so we would expect the Zymo kit to be more likely to perform differently and chose the kit most likely to yield differences. We collected 14 wild frogs (R. catesbeiana and R. sphenocephala) as available from field sites near Leesville, Louisiana (USA), in March 2018. Each animal was swabbed following the above protocol, but with 6 swabs in total: swabbed twice with 3 swabs each time. These swab replicates from the same animal allowed for technical replicates for each extraction method. A subset of swabs from each animal was haphazardly chosen to be extracted using 1 of 2 extraction methods: Qiagen DNeasy Blood and Tissue or Zymo Quick DNA miniprep kit. A total of 42 samples were extracted per kit (14 animals $\times 2$ extraction methods $\times 3$ replicate swabs $=84$ extractions in total).

It is possible that swabbing 'wipes off' available $B d$ cells, where each sequential swab would collect fewer $B d$ cells. However, we do not believe that this would bias our results. First, standard swab method protocols, while as regimented and controlled for as possible, often result in large quantification error, and we suspect that sequential swabbing would have a relatively small effect on the overall amount of error produced in the swabbing process (which includes animal handling, another uncontrolled/untested mechanism for 'wiping off' zoospores). Second, the animals swabbed in this study were large ranid frogs; it is unlikely that our small swabs covered enough skin area to successfully 'wipe off' zoospores.

Live animal samples were extracted following the protocols describe above (along with one positive [spiked sample with culture-grown $B d$ ] and negative [clean swab] extraction control per extraction method) and analyzed using the qPCR methods described above. All individually extracted samples were analyzed via triplicate qPCR reactions. The template DNA for the PrepMan Ultra extraction was diluted (6:100 in molecular grade water), but the template DNA from the spin column kits was not diluted for qPCR. For each extracted sample that was determined to be $B d$ positive ( 2 or more qPCR wells were $B d$ positive), the qPCR values were averaged across the triplicate wells to give $B d$ DNA quantity and calculated as whole-swab $B d$ DNA quantity.

\subsection{Statistical analysis}

All analyses were completed in R, using the RStudio interface (RStudio Team 2016, R Core Team 2018), and we determined that the response variables were normally distributed (i.e. the response variables were not zero-skewed and the residuals were 
normally distributed), and therefore we used linear models for analysis of the data. Where appropriate, we conducted Tukey's post hoc analyses to determine differences among the fixed effects using the R package 'emmeans' (Lenth et al. 2018).

\subsubsection{Threshold of detection}

We used a linear model (LM) on the Qiagen DNeasy Blood and Tissue extraction from known quantity $B d$ standards to compare $B d$ DNA quantities detected using each extraction method across our series of $B d$ dilutions. The dependent variable was logtransformed DNA copies, as determined by qPCR for each sample, and the fixed effect was number of $B d$ zoospores added to the sample (1, 10, 100, 1000, and 10000 ZEs, log transformed) and serial dilution set (we made 2 sets of serial dilutions, see Section 2.1). The standard for 0.1 zoospores added was not included in the analysis to maintain a normal distribution of the residuals because no qPCR reaction returned a positive result at this low standard. To determine the consistency of detecting $B d$ at specific quantities ( $\log _{10}$ zoospores added), we ran several regressions, first using the whole data set, then only standards of $0-2 \log _{10}$ ZEs (the lower load half of the data set), and finally using standards with 2-4 $\log _{10}$ zoospores added (the upper load half of the data set). We report adjusted $\mathrm{R}^{2}$ values calculated via the ' $\mathrm{l} \mathrm{m}$ ' base $\mathrm{R}$ package function and calculated the standard deviation of the $\mathrm{R}^{2}$ using the package 'simpleboot' (Peng 2019).

For the other extraction methods (PrepMan Ultra, Chelex resin, IBI gMAX mini kit and Zymo Quick DNA miniprep), we have also identified the threshold of detection in Text S1.

\subsubsection{Extraction method comparison}

Using known quantity $B d$ samples, we compared the Qiagen DNeasy Blood and Tissue, PrepMan Ultra, and Chelex resin extraction methods using an LM. In this model, $\log _{10}$ DNA copies per sample was the dependent variable, and the effects were zoospores added (100, 1000, and $10000 \mathrm{ZEs}, \log$ transformed), extraction method, and the interaction between zoospores added and extraction method. We did not include the 2 lowest $B d$ quantities added ( 0.1 and 1 zoospores added per sample) in the analysis to prevent a zero-skewed data set and maintain a normal distribution of the residuals, because all qPCR analyses at this $B d$ quantity resulted in only $0 B d$ DNA detected for all extraction kits.

Using known quantities of $B d$, we compared the 3 spin column extraction methods using an LM, where $\log _{10}$ DNA copies per sample was the dependent variable, and the effects were zoospores added, extraction method (Qiagen DNeasy Blood and Tissue, Zymo Quick DNA miniprep, IBI gMAX mini extraction kit), and the interaction between zoospores added and extraction method. Similar to the analyses above, the lowest $2 B d$ standards ( 0.1 and 1 zoospores added) were excluded from the analyses because all samples were $B d$ negative.

\subsubsection{Comparison of extraction methods on field samples}

For the comparison of extraction methods on field samples, we conducted 2 analyses. First, to determine the detection of $B d$ across our series of $B d$ dilutions, we used a generalized linear mixed effects model (GLME) in the 'Ime4' package (Bates et al. $2015)$ with a binomial distribution where the dependent variable was $B d$ status $(B d$ 
detected or not detected) of the extracted sample, the fixed effect was DNA extraction method (PrepMan Ultra or Qiagen DNeasy Blood and Tissue; Qiagen DNeasy Blood and Tissue or Zymo Quick DNA miniprep), and individual was a random effect. Second, to compare $B d$ DNA quantity detected via qPCR between extraction methods, we used a linear mixed effects model (LME), where the dependent variable was $B d$ DNA copies detected ( $\log _{10}$ transformed) of samples that were determined $B d$ positive in both extraction methods, the dependent variable was extraction kit, and individual was a random effect.

We conducted separate analyses for comparing Qiagen DNeasy Blood and Tissue and PrepMan Ultra kits separately from the comparison of Qiagen DNeasy Blood and Tissue and Zymo Quick DNA miniprep extracted field samples.

\section{RESULTS}

\subsection{Threshold of detection using Qiagen DNeasy Blood and Tissue kit}

When all standards were included in the analysis, there was a strong correlation between the number of zoospores added to the samples and the number of $B d$ DNA copies detected via qPCR (LM: $\log _{10}$ zoospores added, $F_{27}=201.530, \mathrm{p}<0.001$, serial dilution, $F_{2}=0.454, \mathrm{p}=0.506, \mathrm{R}^{2}=0.873$, bootstrapping $\mathrm{SD}=0.087 ; \mathbb{F} i g \circ \mathbb{1}$ ), and there was no effect of serial dilution on the results. However, when we split this analysis up, there was a clear difference in the correlation detected at low $B d$ quantity compared with the correlation at high $B d$ quantity (Fig. 1), where quantification of DNA copies for samples with greater than 100 zoospores added was more precise (LM: $\log _{10}$ zoospores added, $F_{15}=40.534, \mathrm{p}<0.001, \mathrm{R}^{2}=0.695$, bootstrapping $\mathrm{SD}=0.188$ ) than for samples with less than 100 zoospores added ( $\log _{10}$ zoospores added, $F_{15}=834.487, \mathrm{p}<0.001, \mathrm{R}^{2}$ $=0.980$, bootstrapping SD $=0.040$; Table S1).

\subsection{Comparing extraction method efficiencies}

\subsubsection{Spin column vs. non-spin column}

When we compared the Qiagen DNeasy Blood and Tissue, PrepMan Ultra, and Chelex resin extraction methods, we found an effect of extraction method on the quantity of $B d$ detected via qPCR (LM: extraction method, $F_{2,21}=3.667, \mathrm{p}=0.043$ ) where the Chelex resin method was statistically different from the Qiagen DNeasy Blood and Tissue extraction (Fig. 2A), but the Qiagen DNeasy Blood and Tissue and PrepMan Ultra were not different from each other, nor were the PrepMan Ultra and the Chelex resin extraction methods (Tukey's post hoc: Chelex resin-Qiagen DNeasy Blood and Tissue, $\mathrm{p}=0.04$; Chelex resin_PrepMan Ultra, $\mathrm{p}=0.167$, Qiagen DNeasy Blood and TissuePrepMan Ultra, $p=0.743$ ). There was a clear increase in DNA copies detected with an increase in the number of zoospores added to the samples (LM: $\log _{10}$ zoospores added, $\left.F_{1,21}=91.644, \mathrm{p}<0.001\right)$, and no interaction effect of extraction method and zoospores added (LM: extraction method $\times \log _{10}$ zoospores added, $F_{1,21}=0.850, \mathrm{p}=0.442$; Table S1)

\subsubsection{Comparing spin column kits}


All 3 spin column extraction methods (IBI gMAX mini kit, Zymo Quick DNA miniprep, and Qiagen DNeasy Blood and Tissue) yielded similar results, and no differences were observed among the different extraction kits (LM: extraction method, $F_{2,30}=0.184, \mathrm{p}=0.833$; Fig. $\left.2 \mathrm{~B}\right)$, and no interaction effect between zoospores added and extraction method (LM: zoospores added $\times$ extraction method, $F_{2,30}=0.062, \mathrm{p}=0.940$ ). There was a clear increase in DNA copies detected with an increase in the number of zoospores added to the samples (LM: $\log _{10}$ zoospores added, $F_{1,30}=501.698, \mathrm{p}<0.001$; Table S1).

\subsection{Extraction kit comparison using field samples}

When we compared the qPCR results of skin swabs collected from the same field collected animal (animals sampled in Pennsylvania in July 2017), we found that the Qiagen DNeasy Blood and Tissue extraction method was able to detect $B d$ more often than the PrepMan Ultra method (Fig. 3A; GLME: $\left.\chi^{2}{ }_{1}=22.409, p<0.001\right)$. Of the 39 animals that were sampled, all animals tested positive for $B d$ in at least 1 of the swabs extracted: 17 animals were $B d$ positive in both swabs, 23 were positive with Qiagen DNeasy Blood and Tissue only. We found that there was a 2.29 times greater likelihood of detecting a true positive $B d$ sample when using the Qiagen DNeasy Blood and Tissue kit versus the PrepMan Ultra method; $43.6 \%$ of the samples were positive using PrepMan Ultra extraction, while 100\% were positive using Qiagen DNeasy Blood and Tissue extraction (see Table S2). Of those samples that were positive for $B d$ in both extraction methods, we found no effect of extraction method on the quantity of $B d$ detected in those samples (LME: $\left.\chi^{2}{ }_{1}=0494, p=0.482\right)$. No inhibition was detected in any of the qPCR reactions (IPC results were equivalent among all reactions).

When comparing qPCR detection of $B d$ DNA from field-collected skin swab samples (animals sampled in Louisiana in March 2018) extracted using the Qiagen DNeasy Blood and Tissue and Zymo Quick DNA miniprep spin column extraction (3 biological replicates per swab method per individual), we found that detection and quantification of $B d$ DNA did not differ between these 2 kits (Fig. 3B). In this set of samples, $42.86 \%$ of the animals ( 6 individuals) tested positive in all samples collected, and $21.43 \%$ ( 3 individuals) were negative for $B d$ in all samples. Of the other 5 individuals, 1 was positive for $B d$ in 1 to 3 of the samples analyzed (Table S3). Both kits returned similar results with no difference in the proportion of $B d$-infected animals detected (GLME: kit, $\chi^{2}{ }_{1}=0.515, p=0.473$ ), nor was there an effect on the quantity of $B d$ detected (LME: kit, $\chi^{2}{ }_{1}=1.78, \mathrm{p}=0.182$ ). Interestingly, these results demonstrate that when infection quantities are low ( $<3 \log _{10}$ DNA copies), our ability to quantify the $B d$ DNA copies present in a sample is imprecise, and false negatives (because replicate swabs taken of the same individual were positive for $B d$ ) are common (see large hinges and whiskers in Fig. 3B). No inhibition was detected in any of the qPCR reactions (IPC results were equivalent among all reactions).

\section{DISCUSSION}

The purpose of this study was to compare different extraction methods commonly used for $B d$ DNA detection and determine which are more efficient at detecting $B d$ infections of amphibians. When comparing extraction methods for lab-created $B d$ 
samples, we found that the Chelex resin method detected higher maximum $B d$ DNA copies when the samples contained high numbers of $B d$ zoospores, while the PrepMan Ultra and spin column extraction methods yielded equivalent results (Fig. 2, Table S1). When we expanded our trial to include field-collected samples, we found that the spin column extraction kits were better than non-spin column methods, especially at detecting $B d$ DNA on animals with low numbers of $B d$ zoospores.

While spin column extraction methods were more efficient for detecting liveanimal $B d$ DNA using qPCR, we also found that all extraction methods were inconsistent at quantifying low levels of $B d$ DNA (Figs. $1 \& 3$, Text S1). When $B d$ quantity was higher ( $>100$ zoospores added), efficiency of detecting $B d$ DNA was high (Fig. 1). Interestingly, at low $B d$ quantities ( $<100$ zoospores added), $B d$ quantity estimates were highly variable, and sometimes returned false negative results (Figs 1 \& 3B, Table S3). Quantifying $B d$ DNA for samples with light $B d$ infections will yield inaccurate results because of this detection threshold. Due to the limits of the technology, $B d$ quantities should be interpreted with caution when $B d$ loads are low.

We found a meaningful difference between the detection of $B d$ in samples collected from live animals and lab-created $B d$ standards prepared with cultured $B d$ cells. Previous research using lab-created $B d$ cultures has tested for differences between extraction methods (specifically PrepMan Ultra and Qiagen DNeasy Blood and Tissue), and found that Qiagen DNeasy Blood and Tissue is a more efficient method for detecting $B d$ via qPCR (Bletz et al. 2015, Sabino-Pinto et al. 2019). Unlike previous studies, we found no measurable differences between the Qiagen DNeasy Blood and Tissue and the PrepMan Ultra extraction methods in terms of $B d$ DNA copies detected via qPCR from lab-created $B d$ standards (Fig. 2A). However, when those 2 extraction methods were compared using samples from live animals, we were more than twice as likely to detect infection in a sample extracted with the Qiagen DNeasy Blood and Tissue spin column compared to the PrepMan Ultra extraction. When a PrepMan Ultra extracted sample was able to detect $B d$ (i.e. when $B d$ present in the sample was high, $\sim 100$ zoospores), the quantity of $B d$ detected was equivalent to the quantity detected in the same Qiagen DNeasy Blood and Tissue extracted sample (Figs. 1 \& 2).

Previous research exploring different extraction methods has indicated that imperfect detection is likely prevalent within the $B d$ literature (Miller et al. 2012, DiRenzo et al. 2018). Imperfect detection is true for nearly all disease diagnostics, because there is always a detection threshold (i.e. a minimum number of pathogen particles required for the test to return a positive result) (Nusser et al. 2008, Miller et al. 2012). One method to overcome imperfect detection suggested by DiRenzo et al. (2018) is to swab animals multiple times, with at least 2 swabs suggested in order to detect 3-5 ZEs, or 4 swabs to detect 1 ZE. Notably, the extraction method used by DiRenzo et al. (2018) was PrepMan Ultra, which our results show is less efficient than the Qiagen DNeasy Blood and Tissue method at detecting low $B d$ infections. We suggest that instead of extracting multiple swabs per animal to detect a low quantity of $B d$ cells with the precision of 3-5 ZEs as DiRenzo et al. (2018) suggested, extracting 1 sample per animal with a more sensitive extraction kit, such as a spin column kit, might be more cost and time effective, and an equally valid way to improve our ability to detect the presence of $B d$. 
Many amphibian species around the world are susceptible to chytridiomycosis (both $B d$ and $B s a l$ ) (Skerratt et al. 2007, Scheele et al. 2019), and the ability to detect very low $B d$ infection prevalence and intensity is imperative for biosecurity of pathogen spread and conservation management. However, pathogen detection at low pathogen quantity is easily missed by single samples as the field component of our study indicates, regardless of extraction method (Fig. 3). In some cases, especially in clinical infection experiments or amphibian species on the verge of extinction, knowing with absolute certainty the infection status of individuals is critical. In these situations, early pathogen detection (at low infection intensities and prevalence) can allow for management action to take place prior to full disease outbreak. Byrne et al. (2018) discussed how experimental outcomes from clinical infection trials can become complicated if negative control animals are not truly $B d$-negative. In that study, wild-caught animals came into the lab with undetectable low $B d$ infections; only after the experiment began did infection become detectable, and cross-contamination was unlikely (based on $B d$ phylogeny data; Byrne et al. 2018). We demonstrate that animals with low $B d$ quantities yield inconsistent $B d$ detection and quantity results (Fig. 3B). In studies where $B d$ infection intensity is low, caution should be used when inferring $B d$ quantity, and the focus should primarily be on detecting the presence/absence of $B d$. If it is imperative to detect $B d$ DNA with precision at low $B d$ infection intensities, we recommend collecting multiple swabs per animal (as suggested by DiRenzo et al. 2018), using a spin column extraction method, and analyzing the samples via qPCR in triplicate (see Table S1).

For researchers deciding among extraction methods, it is important to consider that in the amphibian- $B d$ system, pathogen detection does not always mean disease presence. For many amphibian species on which $B d$ research is currently being conducted, extreme precaution to detect every instance of the pathogen is likely unnecessary. For example, there are many species that exhibit high tolerance/resistance to this pathogen; these species have high recovery and survival if infected, with low infection dynamics in the wild (Daszak et al. 2004, Brannelly et al. 2012a, 2018a,b, Reeder et al. 2012). In systems and studies where extreme precaution is unnecessary, detecting the presence of extremely low $B d$ quantity might not be useful. Further, even in susceptible populations, low infection intensity and prevalence might not indicate disease within the population because animals with low infection intensity are often more likely to recover from infection (Phillott et al. 2013, Brannelly et al. 2015). Our results indicate that when $B d$ infection is high ( $\sim 100$ zoospores or more), the quantity of $B d$ DNA detected was equivalent among extraction methods (PrepMan Ultra and the spin column extraction methods). However, when infections are low, the likelihood of detecting low $B d$ DNA quantities improves when using the spin column extraction kits. We recommend that researchers conduct a cost-benefit analysis when choosing an extraction method and understand the limitations of the extraction methods. For species that are particularly susceptible to $B d$ and low infection detection is important, we recommend using a spin column extraction method.

Acknowledgements. We thank Michel Ohmer, Lydia Zimmerman, Trina Wantman, Jakub Zegar, and Phoebe Reuben with help collecting the field samples; Caitlin Nordheim for help analyzing the samples; and Veronica Saenz, Jamie Voyles, Kimberly Chen, Lee 
519 Berger, and Mary Toothman for providing and maintaining the $B d$ strains. We thank

520 Chris Davis, Jessica Barabas, Abdul Jabbar, and the Pymatuning Laboratory of Ecology

521 for providing the lab space to conduct some of the molecular work. The work was funded

522 through the Australian Research Council Discovery for Early Career Research Award

523 scheme (DE180101395), the University of Melbourne's Faculty of Veterinary and

524 Agricultural Sciences, University of Pittsburgh's Dietrich School of Arts and Sciences,

525 the US National Science Foundation (IOS: Project No. 1649443), and the US Department

526 of Defense (SERDP: Project No. RC-2638). This research was conducted under the

527 University of Pittsburgh Institutional Animal Care and Use Committee protocol

528 16027711. Animal surveys were conducted with permission from the Pennsylvania Fish

529 and Boat Commission (permit 2017-01-0177), and from the Louisiana Department of

530 Wildlife and Fisheries (permit LNHP-17-029).

531

532

533

534

535

536

537

538

539

540

541

542

543

544

545

546

547

548

549

550

551

552

553

554

555

556

557

558

559

\section{LITERATURE CITED}

$<$ jrn $>$ Bates D, Maechler M, Bolker B, Walker S (2015) Fitting linear mixed-effects models using lme4. J Stat Softw 67:1-48 doi:10.18637/jss.v067.i01</jrn>

$<$ jrn>Bletz MC, Rebollar EA, Harris RN (2015) Differential efficiency among DNA extraction methods influences detection of the amphibian pathogen Batrachochytrium dendrobatidis. Dis Aquat Org 113:1-8 PubMed doi:10.3354/dao02822</jrn>

$<$ jrn $>$ Boyle DG, Boyle DB, Olsen V, Morgan JAT, Hyatt AD (2004) Rapid quantitative detection of chytridiomycosis (Batrachochytrium dendrobatidis) in amphibian samples using real-time Taqman PCR assay. Dis Aquat Org 60:141-148 PubMed doi:10.3354/dao060141 $</$ jrn $>$

$<$ jrn>Brannelly LA, Chatfield MWH, Richards-Zawacki CL (2012a) Field and laboratory studies of the susceptibility of the green treefrog (Hyla cinerea) to Batrachochytrium dendrobatidis infection. PLOS ONE 7:e38473 PubMed doi:10.1371/journal.pone.0038473 $<$ /jrn $>$

$<$ jrn>Brannelly LA, Richards-Zawacki CL, Pessier AP (2012b) Clinical trials with itraconazole as a treatment for chytrid fungal infections in amphibians. Dis Aquat Org 101:95-104 PubMed doi:10.3354/dao02521 </jrn $>$

$<$ jrn>Brannelly LA, Hunter DA, Lenger D, Scheele BC, Skerratt LF, Berger L (2015) Dynamics of chytridiomycosis during the breeding season in an Australian alpine amphibian. PLOS ONE 10:e0143629 PubMed doi:10.1371/journal.pone.0143629 $</$ jrn $>$

$<$ jrn $>$ Brannelly LA, Chatfield MWH, Sonn J, Robak M, Richards-Zawacki CL (2018a) Fungal infection has sublethal effects in a lowland subtropical amphibian population. BMC Ecol 18:34 PubMed doi:10.1186/s12898-018-0189-5</jrn>

$<$ jrn>Brannelly LA, Webb RJ, Hunter DA, Clemann N and others (2018b) Non-declining amphibians can be important reservoir hosts for amphibian chytrid fungus. Anim Conserv 21:91-101 doi:10.1111/acv.12380</jrn>

$<$ jrn>Byrne AQ, Poorten TJ, Voyles J, Willis CKR, Rosenblum EB (2018) Opening the 
file drawer: unexpected insights from a chytrid infection experiment. PLOS ONE 13:e0196851 PubMed doi:10.1371/journal.pone.0196851</jrn>

$<$ jrn>Chatfield MWH, Brannelly LA, Robak MJ, Freeborn L, Lailvaux SP, RichardsZawacki CL (2013) Fitness consequences of infection by Batrachochytrium dendrobatidis in northern leopard frogs (Lithobates pipiens). EcoHealth 10:90-98 PubMed doi:10.1007/s10393-013-0833-7</jrn $>$

$<$ jrn $>$ Daszak P, Strieby A, Cunningham AA, Longcore JE, Brown CC, Porter D (2004) Experimental evidence that the bullfrog (Rana catesbeiana) is a potential carrier of chytridiomycosis, an emerging fungal disease of amphibians. Herpetol J 14:201$207<$ jrn $>$

$<$ jrn $>$ DiRenzo GV, Campbell Grant EH, Longo AV, Che-Castaldo C, Zamudio KR, Lips KR (2018) Imperfect pathogen detection from non-invasive skin swabs biases disease inference. Methods Ecol Evol 9:380-389 doi:10.1111/2041-210X.12868</jrn>

$<$ jrn $>$ Garland S, Wood J, Skerratt LF (2011) Comparison of sensitivity between real-time detection of a TaqMan assay for Batrachochytrium dendrobatidis and conventional detection. Dis Aquat Org 94:101-105 PubMed doi:10.3354/dao02327</jrn>

$<$ jrn $>$ Hyatt AD, Boyle DG, Olsen V, Boyle DB and others (2007) Diagnostic assays and sampling protocols for the detection of Batrachochytrium dendrobatidis. Dis Aquat Org 73:175-192 PubMed doi:10.3354/dao073175 </jrn>

$<$ bok $>$ Lenth R, Singmann H, Love J, Buerker P, Herve M (2018) Package 'emmeans': estimated marginal means, aka least-squares means. CRAN. $</$ bok $>$

$<$ jrn>Longcore JE, Pessier AP, Nichols DK (1999) Batrachochytrium dendrobatidis gen. et sp. nov., a chytrid pathogenic to amphibians. Mycologia 91:219-227 doi:10.1080/00275514.1999.12061011 $<$ jrn $>$

$<$ jrn>Martel A, Spitzen-van der Sluijs A, Blooi M, Bert W and others (2013) Batrachochytrium salamandrivorans sp. nov. causes lethal chytridiomycosis in amphibians. Proc Natl Acad Sci USA 110:15325-15329 PubMed doi:10.1073/pnas.1307356110</jrn $>$

$<$ jrn $>$ Miller DAW, Talley BL, Lips KR, Campbell Grant EH (2012) Estimating patterns and drivers of infection prevalence and intensity when detection is imperfect and sampling error occurs. Methods Ecol Evol 3:850-859 doi:10.1111/j.2041$\underline{210 X .2012 .00216 . X}</$ jrn $>$

$<$ jrn $>$ Nusser SM, Clark WR, Otis DL, Huang L (2008) Sampling considerations for disease surveillance in wildlife populations. J Wildl Manag 72:52-60 doi:10.2193/2007-317</jrn>

$<$ bok $>$ Peng RD (2019) Package 'simpleboot': simple bootstrap routines. CRAN. $</$ bok $>$

$<$ jrn $>$ Phillott AD, Grogan LF, Cashins SD, McDonald KR, Berger L, Skerratt LF (2013) Chytridiomycosis and seasonal mortality of tropical stream-associated frogs 15 years after introduction of Batrachochytrium dendrobatidis. Conserv Biol 27:1058-1068 PubMed doi:10.1111/cobi.12073 $</$ jrn $>$

$<$ bok $>$ R Core Team (2018) R: a language and environment for statistical computing. R 
610

611

612

613

614

615

616

617

618

619

620

621
Foundation for Statistical Computing, Vienna $</$ bok $>$

$<$ jrn>Reeder NMM, Pessier AP, Vredenburg VT (2012) A reservoir species for the emerging amphibian pathogen Batrachochytrium dendrobatidis thrives in a landscape decimated by disease. PLOS ONE 7:e33567 PubMed doi:10.1371/journal.pone.0033567</jrn>

$<$ bok $>$ RStudio Team (2016) RStudio: integrated development for R. RStudio, Boston, $\mathrm{MA}</$ bok $>$

$<$ jrn $>$ Sabino-Pinto J, Krause ET, Bletz MC, Martel A, Pasmans F, Steinfartz S, Vences M (2019) Detectability vs. time and costs in pooled DNA extraction of cutaneous swabs: a study on the amphibian chytrid fungi. Amphib-Reptil 40:29-39 doi:10.1163/15685381-20181011 </jrn>

$<$ jrn $>$ Scheele BC, Pasmans F, Skerratt LF, Berger L and others (2019) Amphibian fungal panzootic causes catastrophic and ongoing loss of biodiversity. Science 363:14591463 PubMed doi:10.1126/science.aav0379</jrn>

$<$ jrn $>$ Skerratt LF, Berger L, Speare R, Cashins S and others (2007) Spread of chytridiomycosis has caused the rapid global decline and extinction of frogs. EcoHealth 4:125 doi:10.1007/s10393-007-0093-5 </jrn>

$<$ jrn $>$ Walsh PS, Metzger DA, Higuchi R (1991) Chelex ${ }^{\circledR} 100$ as a medium for simple extraction of DNA for PCR-based typing from forensic material. Biotechniques 10:506-513 PubMed $</$ jrn $>$ 
622 Fig. 1. Number of zoospores added to each sample compared to the number of $B d$ DNA 623 copies detected by $\left(\log _{10}\right.$ DNA copies +1$)$ for samples using the Qiagen DNeasy Blood 624 and Tissue extraction method. Each point represents a unique extracted sample, which 625 was an average of $3 \mathrm{qPCR}$ reaction replicates. A total of 6 samples were extracted from 626 each standard for a total of 36 samples extracted and represented here. The 2 trend lines 627 represent the trend lines for low numbers of $B d$ zoospores added to the samples (1-100 628 zoospores, grey line, $\left.\mathrm{R}^{2}=0.695\right)$, and high numbers of $B d$ zoospores $(100-10000$

629 zoospores added, yellow line, $\left.\mathrm{R}^{2}=0.980\right)$. Both trend lines have been extrapolated to the 630 whole range of data. Shading around the lines represents the $95 \%$ confidence interval. On 631 the $y$-axis, 0 indicates $0 B d$ DNA copies detected, and the number of zoospores added is 632 not log transformed.

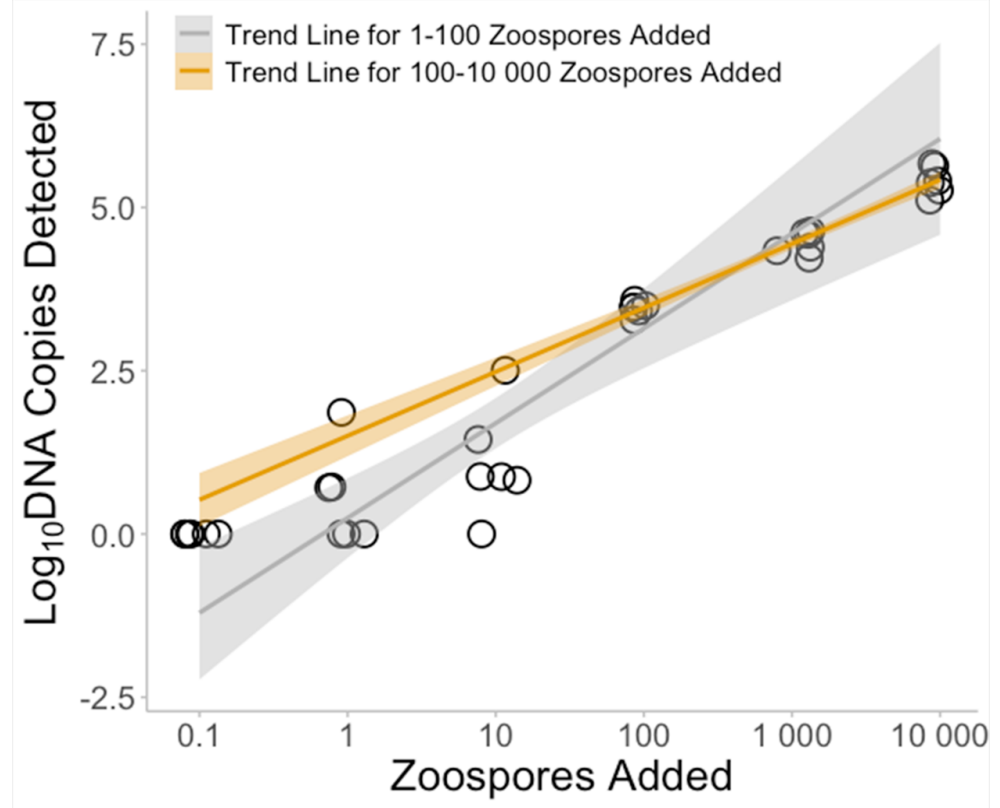

633

634 
635 Fig. 2. Comparison of $B d$ DNA copies detected using different extraction methods of 636 known $B d$ zoospore samples. (A) Comparing the Chelex resin, PrepMan Ultra, and 637 Qiagen DNeasy Blood and Tissue extraction methods ( $B d$ strain MittaMitta-Lspenceri638 2018-LB). Superscripts beside the lines represent statistical differences from each other. 639 (B) Comparing 3 spin column extraction methods: IBI gMAX mini DNA extraction kit, 640 Zymo Quick DNA miniprep extraction kit, and Qiagen DNeasy Blood and Tissue 641 extraction kit ( $B d$ strain MYLF_43). For both panels, 0 on the $y$-axis indicates $0 B d$ DNA 642 copies detected $\left(\log _{10}\right.$ DNA copies +1$)$. Each point represents a unique extracted sample, 643 the lines represent the smoothed conditional means, and color-coded shaded area around 644 the lines represent standard error of the smoothed conditional mean for each extraction 645 method

A

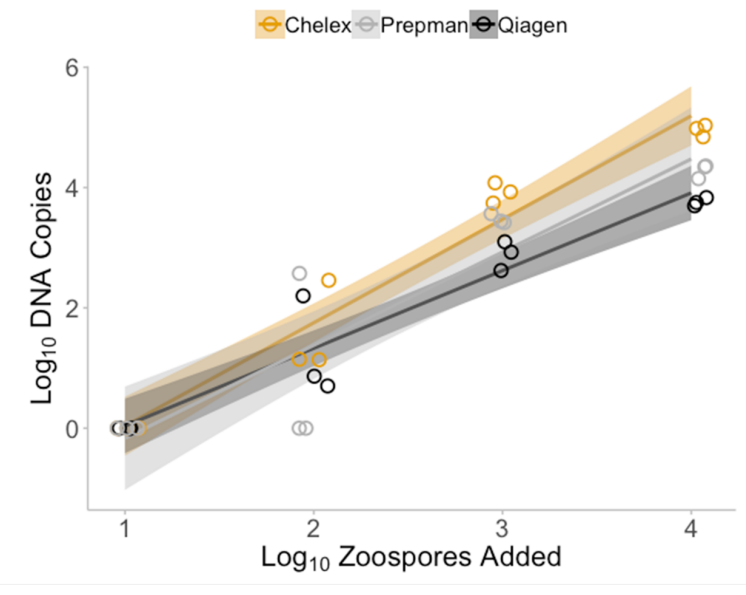

B

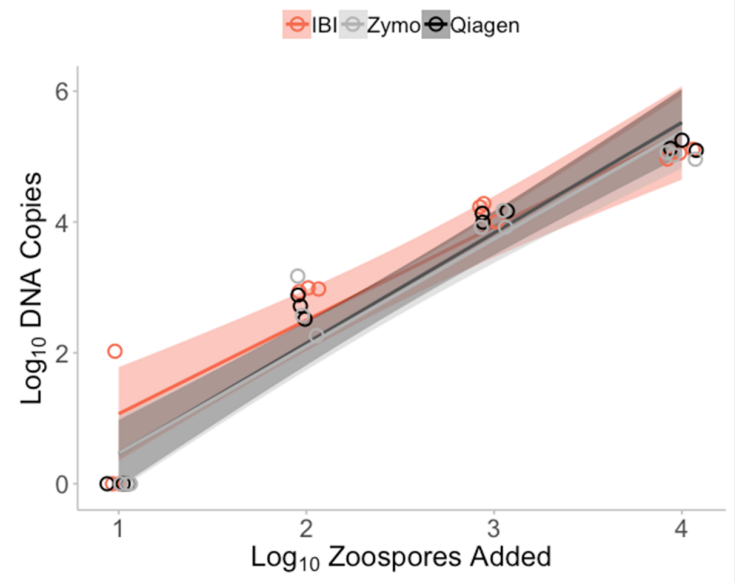


648 Fig. 3. Comparison of $B d$ quantity from field-collected live animal samples. (A)

649 Comparison using the PrepMan Ultra and Qiagen DNeasy Blood and Tissue extraction

650 kits. Two swabs were taken from each animal $(n=39)$, and 1 swab was extracted using

651 each extraction method. The middle line of the box plot represents the median value of

652 samples per extraction method. The upper and lower hinges represent $1^{\text {st }}$ and $3^{\text {rd }}$ quartiles,

653 and the whiskers represent $1.5 \times$ the interquartile range. The open square represents the

654 mean result. (B) Comparison of field-collected samples extracted using the Qiagen

655 DNeasy Blood and Tissue and the Zymo Quick DNA mini extraction kits across the 14

656 individual frogs, where individual is represented along the $x$-axis. Animals were each

657 swabbed 6 times, and 3 samples from each animal were extracted using each extraction

658 method. The middle line of the box plot represents the median value of the 3 samples

659 taken per animal per extraction method. The upper and lower hinges represent $1^{\text {st }}$ and $3^{\text {rd }}$

660 quartiles, and the whiskers represent $1.5 \times$ the interquartile range. In both panels, 0 on the

$661 y$-axis indicates $0 B d$ DNA copies detected $\left(\log _{10}\right.$ DNA copies +1$)$. All samples analyzed

662 are shown, including the samples with no $B d$ DNA copies detected ( $B d$ DNA copies

663 equal to 0 )

A

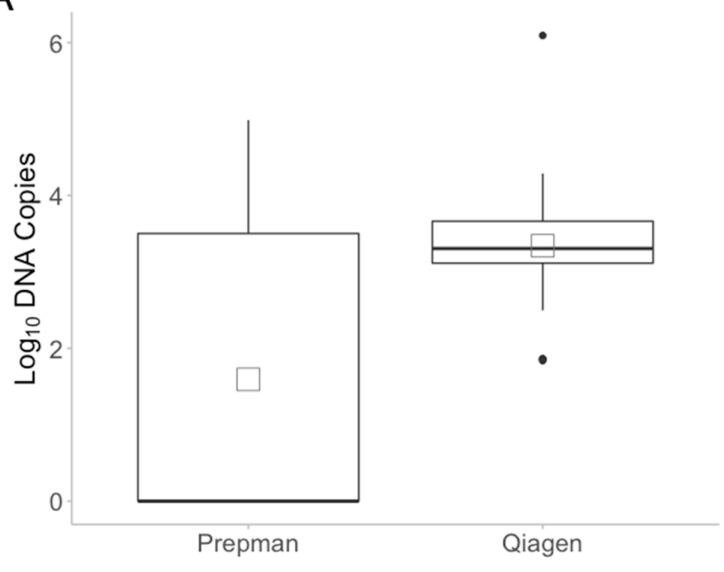

B

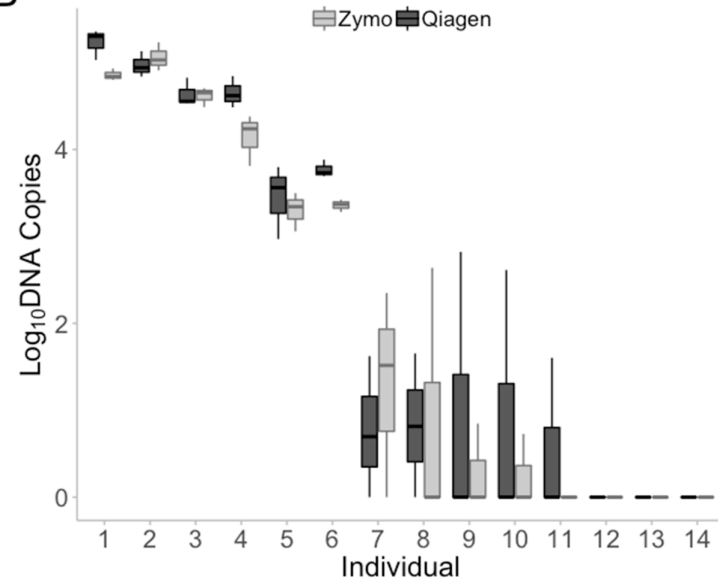




\section{Text S1}

Optimized Batrachochytrium dendrobatidis DNA extraction of swab samples results in imperfect detection particularly when infection intensities are low

Laura A Brannelly, Daniel P Wetzel, Matt West, Corinne L Richards-Zawacki

Additional trial of different PrepMan Ultra and Chelex resin extraction methods

\section{PrepMan Ultra extraction trials}

Using the same standards described in section "Comparison of spin column and nonspin column extraction method", we extracted standard samples (18 samples for each plus 3 negative controls) using two different protocols using PrepMan Ultra, one extraction method using beads and a cell homogenization step (PrepMan with beads), and one method without the beads (PrepMan Alone). Specifically, for the PrepMan alone methods we added $50 \mu \mathrm{L}$ of PrepMan Ultra to each sample, samples were incubated at $95^{\circ} \mathrm{C}$ to lyse the cells for $10 \mathrm{~min}$, then the supernatant was then collected and stored at $-20^{\circ} \mathrm{C}$. For the PrepMan Ultra method including the cell homogenization step (PrepMan with beads), $50 \mu \mathrm{L}$ of PrepMan Ultra and $30-40 \mathrm{mg}$ of $0.5 \mathrm{~mm}$ silica beads was added to each sample, samples were homogenized using a cell homogenizer for $2 \mathrm{~min}$ at 1400 oscillations per sec, incubated at $95^{\circ} \mathrm{C}$ to lyse the cells for $10 \mathrm{~min}$, then the supernatant was then collected and stored at $-20{ }^{\circ} \mathrm{C}$.

Samples were analyzed vis qPCR as described in section "Analysis of the samples using qPCR". All template DNA was diluted 6:100 in molecular grade water, and all samples were analyzed via qPCR in triplicate. A reaction well was considered positive if $>2 B d$ DNA copies amplified. A sample was considered positive if one reaction well was positive, with the quantity of $B d$ determined as an average of all reaction wells (as described in the main document). Negative samples were categorized as having a $B d$ load of 0 .

\section{Chelex resin extraction trial}

Using the same standards described in section "Comparison of spin column and nonspin column extraction method", we extracted standard samples (18 samples for each plus 3 negative controls) using two different protocols using Chelex extraction methods, one with Chelex alone (Chelex Alone), and one with a proteinase $\mathrm{K}$ step added to the extraction (Chelex with PK). For the Chelex extraction method a 5\% Chelex slurry in molecular grade water was made, and $200 \mu \mathrm{L}$ of well mixed slurry was added to each sample. The samples were vortexed and incubated at $95^{\circ} \mathrm{C}$ to lyse the cells for $20 \mathrm{~min}$, then the supernatant was then collected and stored at $-20^{\circ} \mathrm{C}$. For the Chelex with PK extraction, $200 \mu \mathrm{L}$ of well mixed $5 \%$ Chelex slurry and $3 \mu \mathrm{L}$ of Proteinase K (Qiagen \#19131) was added to each sample.

Samples were incubated at $56^{\circ} \mathrm{C}$ to for $60 \mathrm{~min}$ while intermittently vortexing the samples, then incubated at $95{ }^{\circ} \mathrm{C}$ for $15 \mathrm{~min}$. The supernatant was then collected and stored at $-20{ }^{\circ} \mathrm{C}$. For each extraction method, three negative control swab sample (no $B d$ added) was extracted alongside the $B d$-containing samples. qPCR was performed exactly the same as for the PrepMan extraction.

Dilution of Chelex extracted template DNA has not been trialed to our knowledge in the literature. Here we compared 6:100 dilution in DNase free water, and 1:5 dilution of the Chelex and Proteinase K extracted samples.

\section{Statistical analysis}


To compare the efficacy of the two PrepMan extraction methods (PrepMan Alone, and PrepMan with beads), we used a linear model $(\mathrm{lm})$. In this model the DNA copies $\left(\log _{10}\right.$ transformed) per whole sample was the dependent variable, the fixed effects were zoospores added ( $\log _{10}$ transformed) to the sample, extraction method and the interaction between zoospores added and extraction method. Because there were no positive samples below $\log _{10}$ Zoospores $=1$ (10 zoospores added $)$, we only included $1-4$ in the analysis to maintain normal distribution of the residuals for linear regression analysis.

To compare the efficacy of the two Chelex extraction methods (Chelex, and Chelex with Proteinase K), a lm was performed like for the PrepMan extraction method. Similarly, an $\mathrm{lm}$ was performed to comparing the Chelex DNA template dilution.

\section{Results}

When we compared the extraction efficacy using the two different PrepMan extraction methods, we found there was no differences in qPCR results between the two $(1 \mathrm{~m}$ : $\log _{10}$ Zoospores added, $F_{1,20}=141.935, p<0.001$; Method, $F_{1,20}=0.021, p=0.887$, Zoospores added $*$ Method, $\mathrm{F}_{1,20}=0.047, \mathrm{p}=0.83$; Fig S1a). This analysis indicates that PrepMan Ultra extraction can be performed with or without the cell homogenization/bead beating step for effective extraction of $B d$ zoospores. Because of this equivocal result, we chose to include the PrepMan extraction with the bead and cell homogenization step for our methods analysis, because that is the method often reported in the literature.

When we compared the extraction efficacy using the two different Chelex resin extraction methods, we found that including proteinase $\mathrm{K}$ did not affect the amount of $B d$ detected in the sample $\left(\mathrm{lm}\right.$ : $\log _{10}$ Zoospores added, $\mathrm{F}_{1,20}=219.302, \mathrm{p}<0.001$; Method, $\mathrm{F}_{1,20}$ $=3.137, \mathrm{p}=0.092$, Zoospores added $*$ Method, $\mathrm{F}_{1,20}=0.2079, \mathrm{p}=0.653$; Fig S1b). While there is no statistical difference between Chelex extractions with and without Proteinase K, we chose to include the extraction with proteinase $\mathrm{K}$ in the manuscript because that method has been used in $B d$ studies published in the literature.

When we compared the qPCR results for different dilutions of template DNA, we found that higher dilution actually resulted in higher $B d$ DNA quantities $\left(1 \mathrm{~lm}\right.$ : $\log _{10}$ Zoospores added, $\mathrm{F}_{1,20}=236.634, \mathrm{p}<0.001$; Method, $\mathrm{F}_{1,20}=11.725, \mathrm{p}=0.003$, Zoospores added $*$ Method, $\mathrm{F}_{1,20}=2.143, \mathrm{p}=0.159$; Fig S2). This higher efficiency at higher dilution is likely due to inhibitors present in the Chelex resin, although no internal positive controls were added to the samples, therefore we did not test that explicitly. With high potential for inhibitors due to the Chelex extraction method, it is important to test the extraction efficacy on field samples prior to use in the field and we recommend that all qPCR reactions be performed with 6:100 dilution of DNA template if the Chelex resin extraction is conducted. 


\section{Threshold of detection for all extraction methods}

\section{Statistical Analysis}

Threshold detection analysis follows manuscript section 2.4.1, where we ran several linear regressions on the data from each extraction method (Prepman Ultra, Chelex Resin, IBI gMAX mini extraction kit and Zymo Quick DNA miniprep). We used the whole data set for each extraction, the lower half and the upper half of the data set and compared $\mathrm{R}^{2}$ values and the standard deviation of $\mathrm{R}^{2}$ value using bootstrapping as described in the main text. We considered the best model to be the one with the highest $\mathrm{R}^{2}$ value that the standard deviation did not overlap with the $\mathrm{R}^{2}$ values and standard deviations of the other models.

For the Prepman Ultra and the Chelex resin analysis we combined all data from the extraction trials described here in Text S1 (Chelex resin with and without Protinase K; Prepman Ultra with and without a cell homogenization step) because they were shown to be equivocal in results. We analyzed the data as a whole (100,1 000, 10000 zoospores added), fewer zoospores added (100 and 1000 zoospores added) and more zoospores added (1 000 and 10000 zoospores added).

For the IBI gMAX mini extraction kit and Zymo Quick DNA miniprep extraction kits we analyzed the data as a whole (100, 1000,10000 zoospores added), fewer zoospores added (10 and 100 zoospores added) and more zoospores added (1 000 and 10000 zoospores added). Because the sample size for these analyses was smaller, we only performed bootstrapping analysis for the $\mathrm{R}^{2}$ values for the whole data set analysis.

\section{Results}

The accuracy of DNA copies detected under Prepman Ultra extraction methods did not increase with higher loads added to the extraction, indicating that if $B d$ DNA was detected in the well, the quantity reported by qPCR was accurate (Fig S3a) (lm, whole data set: $F_{1,16}=49.92, p<0.001, R^{2}=0.742$, bootstrapping $s d=0.226$; from $100-1000$ zoospores added: $\mathrm{F}_{1,10}=14.57, \mathrm{p}=0.003, \mathrm{R}^{2}=0.552$, bootstrapping $\mathrm{sd}=0.104$; from 1000 -10000 zoospores added: $\mathrm{F}_{1,10}=23, \mathrm{p}<0.001, \mathrm{R}^{2}=0.667$, bootstrapping $\mathrm{sd}=0.203$ ).

Similarly, the accuracy of DNA copies detected under Chelex extraction methods did not increase with higher loads Fig S3b; lm, whole data set: $F_{1,16}=70.55, p<0.001, R^{2}=$ 0.804 , bootstrapping $\mathrm{sd}=0.239$; from $100-1000$ zoospores added: $\mathrm{F}_{1,10}=38.15, \mathrm{p}<0.001$, $\mathrm{R}^{2}=0.772$, bootstrapping $\mathrm{sd}=0.419$; from $1000-10000$ zoospores added: $\mathrm{F}_{1,10}=36.50, \mathrm{p}$ $<0.001, \mathrm{R}^{2}=0.763$, bootstrapping $\left.\mathrm{sd}=0.154\right)$.

The accuracy of DNA copies detected in both the IBI gMAX mini extraction kit and Zymo Quick DNA miniprep extraction kits mirrored what was found in the Qiagen DNeasy Blood and Tissue extraction results (Fig 1), where accuracy in quantity detected is low when few zoospores are present in the sample (Fig S3c,d). The $\mathrm{R}^{2}$ value was lowest when low loads were added to the sample (10 - 100 zoospores) for both extraction methods. While it is possible to detect $B d$ at low loads (under 100 zoospores within the sample), the load estimation is accurate only at higher loads ( 100 zoospores or more within the sample). (IBI gMAX mini extraction kit: $1 \mathrm{~m}$, full data set: $\mathrm{F}_{1,10}=154.30, \mathrm{p}<0.001, \mathrm{R}^{2}=0.933$, bootstrapping $\mathrm{sd}=0.140$; from $10-100$ zoospores added: $\mathrm{F}_{1,4}=35.690, \mathrm{p}=0.004, \mathrm{R}^{2}=$ 0.874; from $1000-10000$ zoospores added: $\mathrm{F}_{1,4}=360.7, \mathrm{p}<0.001, \mathrm{R}^{2}=0.986$; Zymo Quick DNA miniprep extraction kit, $1 \mathrm{~m}$, full data set: $\mathrm{F}_{1,10}=196.2, \mathrm{p}<0.001, \mathrm{R}^{2}=0.947$, bootstrapping $s d=0.132$; from $10-100$ zoospores added: $F_{1,4}=81.30, p=0.001, R^{2}=$ 0.941; from 1000 - 10000 zoospores added: $\mathrm{F}_{1,4}=201.4, \mathrm{p}<0.001, \mathrm{R}^{2}=0.976$ ). 


\section{Appendix: Supplementary Tables S1-S3}

Optimized Batrachochytrium dendrobatidis DNA extraction of swab samples results in imperfect detection particularly when infection intensities are low

Laura A Brannelly, Daniel P Wetzel, Matt West, Corinne L Richards-Zawacki 
Table S1| Summary of the results from the three cultured $B d$ extraction trials: Qiagen extraction threshold detection, non-spin column trial, spin column trial. Total number of qPCR reaction wells for each dilution is 9: each dilution was extracted in 3 samples, and each sample was analyzed in 3 qPCR reaction wells.

\begin{tabular}{lrccc}
\hline Dilution & $B d$ zoospores added $(\log )$ & $\begin{array}{l}B d \text { DNA Quantity } \\
(\log 10)\end{array}$ & Number of Samples + & Number of Wells + \\
\hline Threshold experiment & & & 0 & \\
A & Negative Control & 0 & 0 & 0 \\
& -1 & 0 & 2 & 3 \\
0 & 0.86 & 3 & 4 \\
1 & 1.05 & 3 & 9 \\
2 & 3.48 & 3 & 9 \\
3 & 4.61 & 3 & 9 \\
4 & 5.57 & 0 & 0 \\
B & 0 & 0 & 0 \\
& Negative Control & 0 & 1 & 4 \\
-1 & 0.24 & 2 & 9 \\
& 0 & 1.13 & 3 & 9 \\
1 & 3.42 & 3 & 9
\end{tabular}

Extraction Method

\begin{tabular}{|c|c|c|c|c|}
\hline \multirow[b]{2}{*}{ Chelex } & \multicolumn{3}{|c|}{ Non-spin column vs Spin column } & \\
\hline & Negative Control & 0 & 0 & 0 \\
\hline \multirow{9}{*}{ Prepman } & -1 & 0 & 0 & 0 \\
\hline & 0 & 0 & 0 & 0 \\
\hline & 1 & 0 & 0 & 0 \\
\hline & 2 & 1.58 & 3 & 4 \\
\hline & 3 & 3.91 & 3 & 9 \\
\hline & 4 & 4.95 & 3 & 9 \\
\hline & Negative Control & 0 & 0 & 0 \\
\hline & -1 & 0 & 0 & 0 \\
\hline & 0 & 0 & 0 & 0 \\
\hline \multirow{9}{*}{ Qiagen } & 1 & 0 & 0 & 0 \\
\hline & 2 & 1.26 & 3 & 5 \\
\hline & 3 & 2.88 & 3 & 9 \\
\hline & 4 & 3.76 & 3 & 9 \\
\hline & Negative Control & 0 & 0 & 0 \\
\hline & -1 & 0 & 0 & 0 \\
\hline & 0 & 0 & 0 & 0 \\
\hline & 1 & 0 & 0 & 0 \\
\hline & 2 & 0.86 & 2 & 2 \\
\hline \multirow{3}{*}{\multicolumn{4}{|c|}{$\begin{array}{c}3.47 \\
4.28 \\
\text { Spin column extraction }\end{array}$}} & 9 \\
\hline & & & & 9 \\
\hline & & & & \\
\hline \multirow[t]{4}{*}{ IBI } & Negative Control & 0 & 0 & 0 \\
\hline & -1 & 0 & 0 & 0 \\
\hline & 0 & 0 & 0 & 0 \\
\hline & 1 & 0.22 & 1 & 1 \\
\hline
\end{tabular}




\begin{tabular}{|c|c|c|c|c|}
\hline Dilution & $B d$ zoospores added $(\log )$ & $\begin{array}{l}B d \text { DNA Quantity } \\
(\log 10)\end{array}$ & Number of Samples + & Number of Wells + \\
\hline & 2 & 2.55 & 3 & 8 \\
\hline & 3 & 4.01 & 3 & 9 \\
\hline & 4 & 4.95 & 3 & 9 \\
\hline \multirow[t]{7}{*}{ Zymo } & Negative Control & 0 & 0 & 0 \\
\hline & -1 & 0 & 0 & 0 \\
\hline & 0 & 0 & 0 & 0 \\
\hline & 1 & 0.23 & 1 & 1 \\
\hline & 2 & 2.51 & 3 & 9 \\
\hline & 3 & 3.83 & 3 & 9 \\
\hline & 4 & 4.82 & 3 & 9 \\
\hline \multirow[t]{7}{*}{ Qiagen } & Negative Control & 0 & 0 & 0 \\
\hline & -1 & 0 & 0 & 0 \\
\hline & 0 & 0 & 0 & 0 \\
\hline & 1 & 0.28 & 1 & 1 \\
\hline & 2 & 2.66 & 3 & 9 \\
\hline & 3 & 4.90 & 3 & 9 \\
\hline & 4 & 5.57 & 3 & 9 \\
\hline
\end{tabular}


Table S2| Summary of results from the comparison of Prepman and Qiagen extracted field swabs. Each individual was doubly swabbed, and the swab was randomly assigned to either Qiagen or Prepman extraction. for each extracted swab, it was analyzed in triplicated using qPCR. Number of wells + refers to the number of triplicate reaction wells that returned a $B d$ positive result. qPCR reaction wells were considered positive if there were at least 2 DNA copies present in the reaction well. Sample $B d$ quantity is an average of all reaction wells ( 3 in total) for that sample.

\begin{tabular}{|c|c|c|c|c|c|c|}
\hline \multirow[b]{2}{*}{ ID } & \multirow{2}{*}{\multicolumn{2}{|c|}{ Species }} & $\begin{array}{l}\text { Bd Quantity } \\
(\log 10)\end{array}$ & $\begin{array}{l}\text { Number of } \\
\text { Wells }+\end{array}$ & $\begin{array}{l}\text { Bd Quantity } \\
(\log 10)\end{array}$ & $\begin{array}{l}\text { Number of Wells } \\
+\end{array}$ \\
\hline & & & \multicolumn{2}{|c|}{ Prepman Extraction } & \multicolumn{2}{|c|}{ Qiagen Extraction } \\
\hline & 1 & Rana clamitans & 3.490 & 3 & 2.996 & 3 \\
\hline & 2 & Rana clamitans & & 0 & 1.839 & 2 \\
\hline & 3 & Rana clamitans & & 0 & 1.865 & 2 \\
\hline & 4 & Rana clamitans & & 0 & 1.857 & 2 \\
\hline & 5 & Rana clamitans & & 0 & 3.351 & 3 \\
\hline & 6 & Rana clamitans & & 0 & 2.497 & 3 \\
\hline & 7 & Rana clamitans & & 0 & 3.484 & 3 \\
\hline & 8 & Rana clamitans & & 0 & 3.044 & 3 \\
\hline & 9 & Rana clamitans & 3.448 & 3 & 3.165 & 3 \\
\hline & 10 & Rana clamitans & 0.880 & 1 & 3.110 & 3 \\
\hline & 11 & Rana clamitans & & 0 & 3.265 & 3 \\
\hline & 12 & Rana clamitans & & 0 & 3.059 & 3 \\
\hline & 13 & Rana clamitans & & 0 & 2.942 & 3 \\
\hline & 14 & Rana clamitans & 4.287 & 3 & 3.969 & 3 \\
\hline & 15 & Rana clamitans & & 0 & 3.000 & 3 \\
\hline & 16 & Rana clamitans & 2.969 & 3 & 3.152 & 3 \\
\hline & 17 & Rana clamitans & 4.537 & 3 & 3.669 & 3 \\
\hline & 18 & Rana clamitans & & 0 & 3.165 & 3 \\
\hline & 19 & Rana clamitans & & 0 & 3.260 & 3 \\
\hline & 20 & Rana clamitans & 4.212 & 3 & 3.647 & 3 \\
\hline & 22 & Rana clamitans & 3.507 & 3 & 3.520 & 3 \\
\hline & 23 & Rana clamitans & & 0 & 4.055 & 3 \\
\hline & 24 & Rana clamitans & & 0 & 3.733 & 3 \\
\hline & 25 & Rana clamitans & & 0 & 3.386 & 3 \\
\hline & 26 & Rana clamitans & 3.425 & 3 & 3.670 & 3 \\
\hline & 27 & Rana clamitans & & 0 & 3.690 & 3 \\
\hline & 28 & Rana clamitans & 3.557 & 3 & 3.481 & 3 \\
\hline & 29 & Rana clamitans & 3.509 & 3 & 6.093 & 3 \\
\hline & 30 & Rana clamitans & & 0 & 3.398 & 3 \\
\hline & 31 & Rana clamitans & 1.948 & 2 & 3.532 & 3 \\
\hline & 32 & Rana clamitans & & 0 & 3.155 & 3 \\
\hline & 33 & Rana clamitans & & 0 & 3.128 & 3 \\
\hline & 34 & Rana clamitans & & 0 & 3.266 & 3 \\
\hline & 35 & Rana catesbeiana & 4.986 & 3 & 3.347 & 3 \\
\hline & 36 & Rana catesbeiana & 3.713 & 3 & 4.288 & 3 \\
\hline & 37 & Rana catesbeiana & 4.612 & 3 & 3.865 & 3 \\
\hline & 38 & Rana catesbeiana & 4.815 & 3 & 3.854 & 3 \\
\hline & 39 & Rana catesbeiana & 2.686 & 3 & 3.243 & 3 \\
\hline
\end{tabular}


Table S3| Summary of results from the comparison of Zymo and Qiagen extracted field swabs. Each individual was swabbed with 6 swabs, and the swabs were randomly assigned to either Qiagen or Zymo extraction. For each extracted swab, it was analyzed in triplicated using qPCR. Number of wells + refers to the number of triplicate reaction wells that returned a $B d$ positive result (a total of 9 wells were analyzed per individual - 3 samples extracted per individual per extraction method, and each sample was analyzed in 3 qPCR reaction wells), and number of samples + refers to the number of swabs for which at least 2 reaction wells were positive.

\begin{tabular}{|c|c|c|c|c|c|c|c|}
\hline \multirow[b]{2}{*}{ Individual } & \multirow[b]{2}{*}{ Species } & $\begin{array}{l}\text { Bd Quantity } \\
(\log 10)\end{array}$ & $\begin{array}{l}\text { Number of } \\
\text { Samples }+ \\
\end{array}$ & $\begin{array}{l}\text { Number of } \\
\text { Wells }+\end{array}$ & $\begin{array}{l}B d \text { Quantity } \\
(\log 10)\end{array}$ & $\begin{array}{l}\text { Number of } \\
\text { Samples }+ \\
\end{array}$ & $\begin{array}{l}\text { Number of } \\
\text { Wells }+\end{array}$ \\
\hline & & \multicolumn{3}{|c|}{ Zymo Extraction } & \multicolumn{3}{|c|}{ Qiagen Extraction } \\
\hline 1 & Rana sphenocephala & 4.858 & 3 & 9 & 5.230 & 3 & 9 \\
\hline 2 & Rana catesbeiana & 5.058 & 3 & 9 & 4.970 & 3 & 9 \\
\hline 3 & Rana catesbeiana & 4.615 & 3 & 9 & 4.639 & 3 & 9 \\
\hline 4 & Rana catesbeiana & 4.143 & 3 & 9 & 4.650 & 3 & 9 \\
\hline 5 & Rana catesbeiana & 3.299 & 3 & 9 & 3.443 & 3 & 9 \\
\hline 6 & Rana catesbeiana & 3.357 & 3 & 9 & 3.769 & 3 & 9 \\
\hline 7 & Rana catesbeiana & 1.288 & 2 & 5 & 0.773 & 2 & 3 \\
\hline 8 & Rana catesbeiana & 0.880 & 1 & 3 & 0.823 & 2 & 3 \\
\hline 9 & Rana catesbeiana & 0.282 & 1 & 1 & 0.941 & 1 & 3 \\
\hline 10 & Rana catesbeiana & 0.243 & 1 & 1 & 0.871 & 1 & 3 \\
\hline 11 & Rana catesbeiana & 0 & 0 & 0 & 0.535 & 1 & 2 \\
\hline 12 & Rana catesbeiana & 0 & 0 & 0 & 0 & 0 & 0 \\
\hline 13 & Rana catesbeiana & 0 & 0 & 0 & 0 & 0 & 0 \\
\hline 14 & Rana catesbeiana & 0 & 0 & 0 & 0 & 0 & 0 \\
\hline
\end{tabular}


3 Optimized Batrachochytrium dendrobatidis DNA extraction of swab samples results in 4 imperfect detection particularly when infection intensities are low

5

6 Laura A Brannelly, Daniel P Wetzel, Matt West, Corinne L Richards-Zawacki 
2 Figure S1. Comparison of extraction efficacy using two variations of A) PrepMan Ultra and 3 B) Chelex Resin extraction methods. A) Prepman Ultra extraction was conducted using beads 4 and a cell homogenizer (PrepMan with Beads), and without (PrepMan Alone). B) Chelex 5 resin extraction was conducted using proteinase K (Chelex with PK), and without (Chelex 6 Alone). Each point represents an individual sample (averaged across triplicate qPCR 7 reactions), the lines represent the smoothed conditional means, and shaded area represent 8 standard error of each extraction method.

A

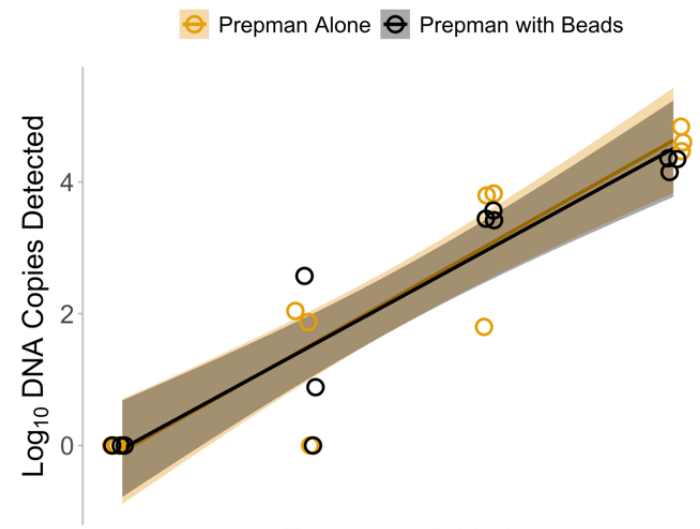

Zoospores Added
B

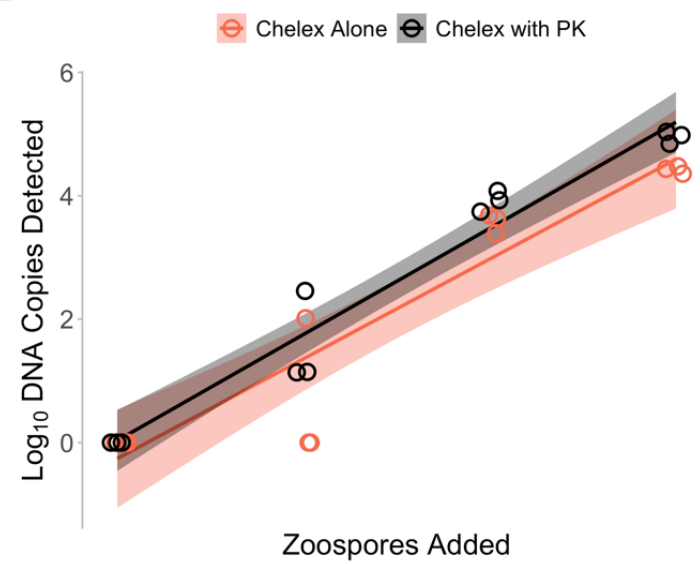

Figure S2. Comparison of DNA template dilution prior to qPCR for the Chelex with

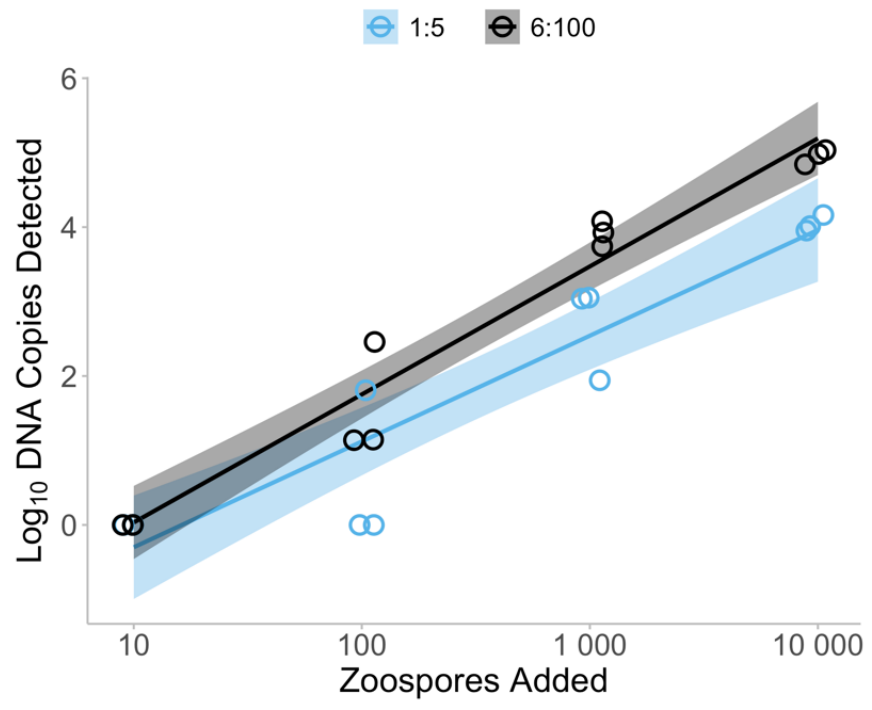


2 Fig S3. Threshold detection for all extraction methods. A) Prepman Ultra and B) Chelex 3 resin, where detection accuracy is similar for different concentrations of zoospores added to 4 the extraction, indicating that as long as the DNA is detected via qPCR, the quantitative 5 results will be accurate. The black line represents the smoothed conditional means of the 6 whole data set, and shaded area represent standard error of the extraction method. C) IBI 7 gMAX mini extraction kit and D) Zymo Quick DNA miniprep extraction kits, where 8 detection accuracy is worse at low loads. The two trend lines represent the trend lines for low 9 numbers of $B d$ zoospores added to the samples (10-100 zoospores added, grey line), and 10 high numbers of $B d$ zoospores added to the samples (1 $000-10000$ zoospores added, pink 11 line). Both trend lines have been extrapolated to the whole range of data. The lines represent the smoothed conditional means, and shaded area represent standard error of the extraction method.

Trend Line for All Zoospores Added Trend Line for 1-100 Zoospores Added

Trend Line for 100-10 000 Zoospores Added

A

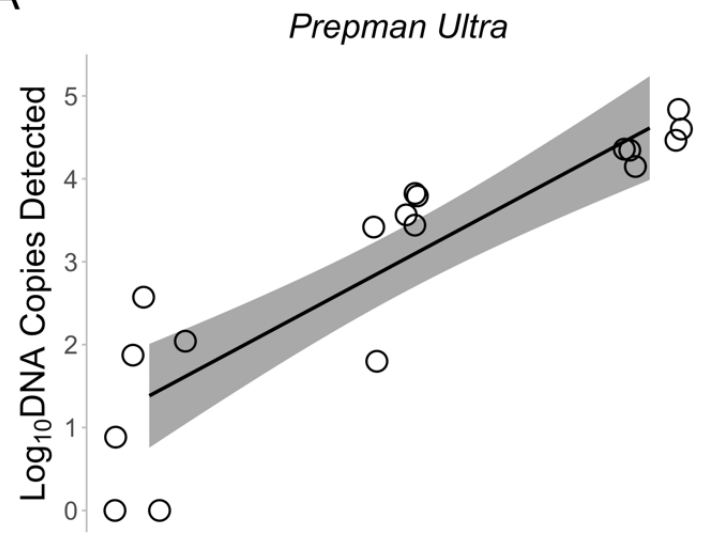

Zoospores Added

B

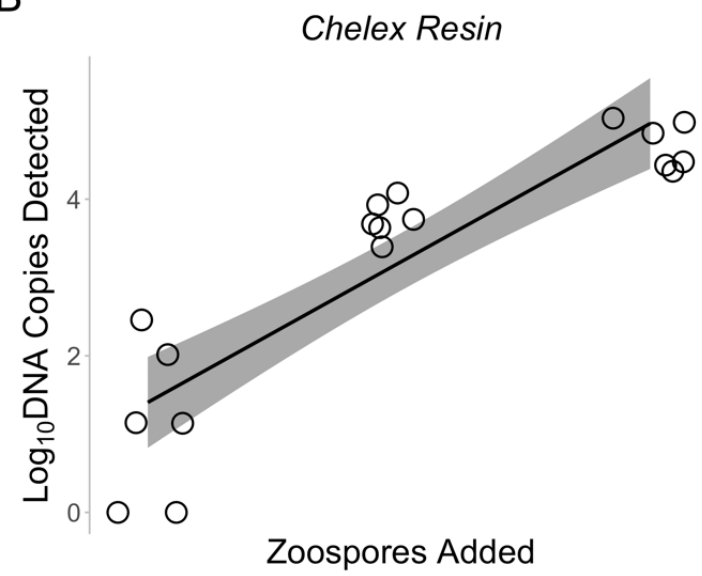

C

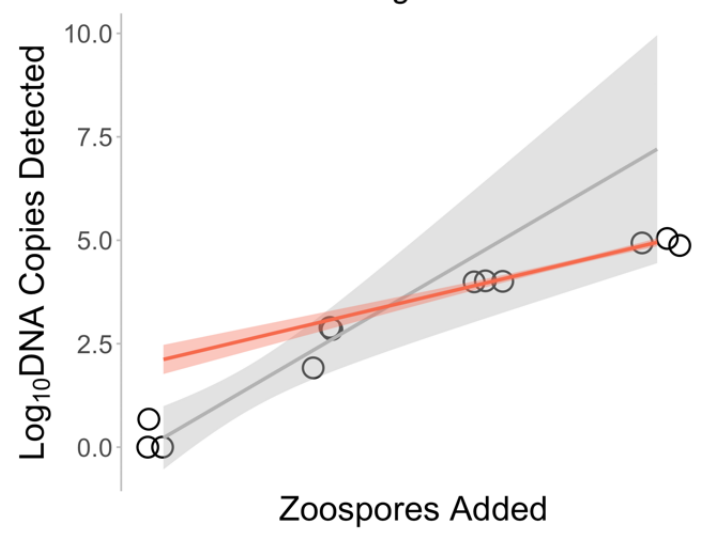

D

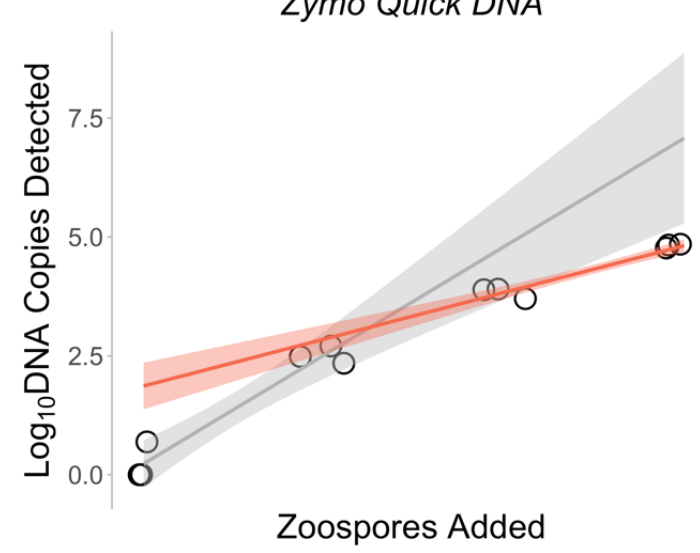




\section{University Library}

\section{- M M I N E R VA \\ A gateway to Melbourne's research publications}

Minerva Access is the Institutional Repository of The University of Melbourne

Author/s:

Brannelly, LA;Wetzel, DP;West, M;Richards-Zawacki, CL

Title:

Optimized Batrachochytrium dendrobatidis DNA extraction of swab samples results in imperfect detection particularly when infection intensities are low.

Date:

2020-06-04

Citation:

Brannelly, L. A., Wetzel, D. P., West, M. \& Richards-Zawacki, C. L. (2020). Optimized Batrachochytrium dendrobatidis DNA extraction of swab samples results in imperfect detection particularly when infection intensities are low.. Diseases of Aquatic Organisms, 139, pp.233-243. https://doi.org/10.3354/dao03482.

Persistent Link:

http://hdl.handle.net/11343/277007 